\title{
СЛОВАРНЫЙ ЗАПАС
}

\section{Сопоставительная характеристика спортивной лексики в русском и узбекском языках в лингводидактических целях}

В статье рассматривается классификация и анализ дифференциального и общего в спортивной лексике русского и узбекского языков, что является одним из важнейших условий научно обоснованной разработки методики ее усвоения учащимися-билингвами, системы формирования как лексико-грамматических, так и коммуникативных умений и навыков. Предпринята попытка условно разделить спортивный пласт лексики на три группы. В первую группу слов отнесены слова, передающие обозначения одних и тех же понятий в русском и узбекском языках. Во-вторую группу вошла лексика, частично различающаяся как графически, так и по грамматической функции. Третью, наиболее многочисленную группу составляет спортивная лексика, совершенно разная по звуковому облику и написанию в русском и узбекском языках.

Ключевые слова: узбекский язык, учащиеся-билингвы, разносистемные языки, спортивная лексика, сопоставление, перевод, лексическое значение, заимствования, опорные слова, научный подстиль.

\section{Цой Марина Климентьевна,} преподаватель Узбекского государственного университета мировых языков (Ташкент), tsoymarisha@yandex.ru
Разные уровни владения русским языком в контексте функционального, целеориентированного двуязычия (расширение, углубление знаний учащихся в школах с углубленным изучением предмета, профильное обучение в старшем звене, специфические задачи обучения в школах со статусом гимназий, колледжей, лицеев и др.) не означают снижение единого базового уровня, уровня государственного стандарта.

Современный уровень развития общества предполагает наличие у учащихся-билингвов устойчиво сформи- 
рованных умений непосредственного общения на родном и русском языках, а также умений, позволяющих оперативно осуществлять опосредованную языковую коммуникацию в процессе делового или профессионального общения. А это невозможно без качественного владения соответствующей лексикой.

Обучение учащихся-билингвов русскому языку, в том числе лексике, будет тем успешнее, чем полнее будут учитываться в процессе работы данные сопоставления разносистемных языков, какими являются русский и узбекский, факты общностей и различий между ними.

Лексика русского языка всегда была предметом пристального внимания, как со стороны лингвистов, так и методистов. Во многих диссертациях, монографиях, статьях достаточно подробно исследованы как общие, так и частные вопросы русской лексикологии. Мало найдется таких языков, как русский, лексика которого описана также в разнообразных словарях - толковых, переводных, этимологических, синонимических, фразеологических, картинных, в словарях трудностей, антонимов и др. Однако до сих пор не созданы двуязычные (русско-узбекский и узбекско-русский) словари спортивной терминологии и лексики, учитывающие специфичность и своеобразие данного пласта слов, на основе которых была бы разработана научно обоснованная система упражнений для узбекских учащихся.

Спортивная лексика представляет собой своеобразный пласт, насыщенный, с одной стороны, лексическими заимствованиями, вошедшими в узбекский язык из русского языка или через его посредство так называемыми общими словами в родном (узбекском) и в русском языках; с другой стороны, лексикой, характерной для спортивного подстиля, не имеющей эквивалентов в сопоставляемых языках. При этом необходимо учитывать следующие обстоятельства: 1) многие спортивные 
термины заимствованы узбекским языком из русского или через него, например баскетбол, волейбол, гимнастика, спорт и др.; 2) в связи с принятием в 1989 г. закона Республики Узбекистан о государственном языке ряд специалистов по современному узбекскому языку настаивает на замене заимствований словами «исконно узбекского языка», что на наш взгляд, не всегда оправданно, ибо за счет заимствований любой язык в известной степени обогащается. Тем не менее, нельзя сбрасывать со счетов то обстоятельство, что в будущем некоторые слова и термины спортивного характера, заимствованные узбекским языком из русского или через его посредство, могут изменить свой статус.

Принцип учета родного языка при изучении неродного, в частности русского, не является дискуссионным и признается как психологами, так и методистами не только в нашей стране, но и за рубежом (Л.С. Выготский, Л.В. Щерба, Е.Д. Поливанов, А.А. Леонтьев, Н.М. Шанский, В.Г. Костомаров, В.В. Решетов, А.А. Азизов, М.Х. Тохтаходжаева, Х.Я. Якубова, Л.Т. Ахмедова, М.Д. Джусупов и др.).

Коммуникативно-ориентированная методика обучения русского языку учащихся-билингвов нацеливает не столько на преодоление родного языка, сколько на рациональное использование его.

В ряде исследований последних лет межъязыковые сопоставления рассматриваются не только как средство продолжения интерференции, но и как средство последовательного проведения в жизнь дидактического принципа сознательности [10], повышения мотивационной готовности учащихся [9], учета транспозиции [2], определения оптимальной методики раскрытия значений лексических единиц и активизации их в речи [8].

Исследование сопоставления в психологическом аспекте включает в себя выявление закономерностей 
взаимодействия русского и родного (узбекского) языков учащихся-билингвов в процессе восприятия и порождения речи. Сопоставление на уровне лексики русского и родного (узбекского) языков должно иметь практическую направленность, то есть «должно подчеркивать лишь те особенности двух языков, которые в той или иной степени затрудняют для узбекского школьника освоение правильной русской речи...» [4, с. 26].

Как показывает практика, опора на родной язык помогает учащимся-билингвам усваивать материал по аналогии, если учитель при объяснении нового материала и введении в речевую практику новых слов, словосочетаний обращает внимание обучаемых на сходные языковые явления, а в случаях расхождения с помощью специально лексико-грамматических упражнений предупреждает возможность появления ошибок, связанных с языковой интерференцией.

По мнению М.Б. Успенского, при межъязыковых сопоставлениях необходимо учитывать и особенности лексической системы сопоставляемых языков [9], в которых обычно сравниваются широкоупотребительные эквиваленты, что, в свою очередь, связано с установлением наиболее общих черт «поверхностного и глубинного характера», на фоне которых выявляется специфика сопоставляемых языков [7].

Необходимо иметь в виду, что «слова одного языка в большинстве случаев не просто соответствуют словам другого языка, а находятся с ними в весьма сложных и многообразных отношениях» [11, с. 67]. Нередко лексическое значение одного языка не находит себе лексического эквивалента в другом языке, поэтому целесообразно систематизировать слова с помощью толкования (описания): акробат - акробат (мохир гимнастикачи; циркда - гимнастика уйинларига уста артист), акробатика - акробатика (одатда циркда кўрсатиладиган му- 
раккаб гимнастика уййнлари, санъати); альпинизм альпинист (альпинизм билан шагулланучи киши) и т. д.

Проблема языковых контактов, в частности на уровне лексики, многоаспектна и многогранна. При переходе из одного языка в другой слова могут осваиваться фонетически, графически, грамматически, лексически. «При фонетическом освоении слово обычно меняет свой звуковой облик, причем изменения звучания может не зависеть от каких-то фонетических законов: при графическом освоении заимствованное слово передается на письме средствами алфавита заимствующего языка (языка - носителя заимствования), - отмечает Л.И. Солнцева. - Грамматическое освоение слов свидетельствует о действии своих грамматических норм (законов) в языке заимствования и вместе с лексическим освоением, при котором слово из языка-источника настолько прочно входит в язык-носитель заимствования, что воспринимается последним как исконное - представляет особый интерес для дальнейшего изучения заимствованных слов, в частности специальных, научно-технических терминов, проблема функционирования которых в художественной, публицистической, научно-популярной речи до сих пор остается одной из наименее изученных» [6, с. 10]. Вот почему необходимо не только качественное освоение лексики вообще (в том числе спортивной), но и изучение ее в необходимых случаях в сопоставительном плане. Это относится прежде всего к тому лексическому пласту, в котором графический облик слов в русском и узбекском языках совпадает.

Лексику, употребляющуюся для обозначения одних и тех же понятий в русском и узбекском языках, мы условно отнесли в первую группу слов. Этот пласт лексики представляет собой однозначные и многозначные русские слова, заимствованные узбекским языком 
с неизменными исходными формами: гантель, гимнаст, зал, зарядка, скачок, инвентарь, инструктор, кандидат, капитан, программа, спортсмен, судъл, табло, тактика и др. Они прочно вошли в лексический фонд узбекского литературного языка, общепонятны и общеупотребительны, поэтому не имеют переводов в родном языке. В современном узбекском литературном языке корни, основы абсолютного большинства таких слов сохраняются и пишутся так же, как и в русском языке. Причем такие слова, как гантель, гимнаст, инструктор, спортсмен, табло имеют одно значение. По два значения отмечено у лексем зал, зарядка, значок, инвентарь, кандидат, тактика. По три значения имеются у слов капитан, судъя, причем в слове судья наблюдается сужение значений, отсутствует первое значение: человек, который судит, высказывает мнение, дает оценку, а в слове программа не совпадает количество значений.

Тем не менее на занятиях русского языка именно этому пласту спортивной лексики необходимо уделить больше внимания, ибо, по справедливому утверждению А.А. Реформатского, звуки, схожие в чужом и родном языках, поддаются усвоению с гораздо большим трудом, чем те, которых нет в родном языке. Е.Д. Поливанов призывал постоянно помнить о существующем в определенных случаях расхождении (иногда существенном) между буквой и обозначаемым ею звуком. Необходимо «всячески использовать графический момент - знаковое слово (в котором можно создать «смешение гласных звуков») должно быть преподносимо аудитории не только в виде слухового впечатления, но и наоборот - главным образом в орфографической своей форме - чтобы и зрительные, и моторные (при написании) кальки поддерживали и облегчали выработку правильного акустического распознавания данных русских звуков (в конкретных позиционных усло- 
виях), использование орфографии на подмогу акустическим и произносительным упражнениям являются, таким образом, обязательной, но вместе с тем с нелегкой задачей для преподавателя...» [5, с. 59-60].

В.М. Бельдиян отмечал: «В узбекском алфавите нет ни одной буквы, которой бы соответствовал такой же комплекс звучаний, как и графически сходной русской букве. Следовательно, основная трудность при обучении чтению заключается не в том, что в русском языке и узбекском много разных звуков, а в том, что и сходные и несходные в разных языках звуки поразному ассоциируются со сходными графемами» [1, c. 23]. Поэтому на занятиях по русскому языку целесообразно сопоставлять в первую очередь заимствованные узбекским языком слова.

Однако обучение лексике указанной категории имеет и свои преимущества: значения данной группы слов полностью совпадают как в русском, так и в узбекском языках. Следовательно, при активизации указанного пласта слов, если нет различий в объеме значений слов в русском и узбекском языках, можно уделить больше времени работе над произношением в синтаксической сочетаемости с другими словами в предложении.

Практика показала, что нередки случаи смешения, то есть неправильного восприятия русских звуков «о» и «у». Например, слово инструктор узбек иногда может записать (под диктовку) как инстроктор и, наоборот, вместо русского «о» он может иногда написать «у» $($ инструктур, кумпас и т. д.). Объясняется это несовпадением критериев звукоразличения между русскими и узбекскими гласными фонемами. В словах указанной группы имеет место и такая фонетическая особенность, как то, что в них конечные звонкие согласные звуки не оглушаются. 
Это явление, характерное для исконно узбекских слов, распространяется и на заимствованную лексику. Так, например, русское заимствование «коллектив» в узбекском языке произносится с конечным звонким «в» (актив, резерв), ринг-с конечным звонким «г», рекорд «д», репортаж - «ж» и т.д. Подобное произношение сохраняется и в тех случаях, когда звонкие согласные находятся в середине слова перед глухими: автобус, автомобиль, блузка, космонавт, справка, юбка и т. д.

Отмечая фонетические особенности заимствования узбекским языком слов, нельзя не коснуться хотя бы в общих чертах вопроса о звуковых комплексах, характерных для спортивной лексики. В этом отношении наиболыший интерес представляют комплексы согласных звуков, в частности, комплексы из двух согласных. Например: баскетбол, гимнаст, грипп, группа, дистаниия, квалификаиия, метр, стадион, стопа и др. И в устной, и в письменной речи узбекских учащихся при стечении согласных возможно появление лишнего звука (эпентеза): гируппа (группа), диситанаиия (дистаниия), устадион или истадион (стадион).

Рассматриваемый пласт спортивной лексики располагает полными соответствиями значений и форм слов в обоих сопоставляемых языках. Но есть и такие слова, «которые при отталкивании от системы родного языка учащихся расширяют объем грамматической функции». [7, с. 42]. Это происходит за счет того, что сходные по форме слова в узбекском языке выступают в роли другой части речи. Сравним:

\begin{tabular}{|l|l|}
\hline В русском языке: & В узбекском языке: \\
\hline марафонский & марафон \\
спортивный & спорт \\
футбольный & футбол \\
хоккейный & хоккей \\
шахматный & шахмат \\
физкультурный & физкультура \\
\hline
\end{tabular}


Подобные слова не входят в выделенную нами условно первую группу и отнесены ко второй группе спортивной лексики - частично различающейся как графически, так и по грамматической функции.

Однако, говоря о внешнем (графический облик слова) и одновременно внутреннем сходстве (соответствие семантики слов в сопоставляемых языках) спортивной лексики в русском и узбекском языках, следует иметь в виду и то, что «словарные соответствия, основывающиеся на сходстве семантического ядра слов, не всегда отражают их реальную роль в речи» [3, с. 115]. Так, рассматривая общие семантические категории (или лексико-семантические группы слов), обычно ориентируются как на данные словарей и на факты языковой системы, так и на данные переводов, отражающие акты речи. При этом акт речи представляет собой двусторонний процесс: восприятие чужого высказывания и порождение собственного. При изучении языковых фактов мы имеем дело с декодированием чужой речи (процесс анализа) и закодированием своей речи (процесс синтеза), что соответствует пассивной и активной грамматике академика Л.В. Щербы [11, с. 78].

Известно, что при рассмотрении лексических фактов основное внимание уделяется процессу анализа (декодированию). Поэтому все общие семантические категории (многозначность, фразеология) определяются с точки зрения пассивного плана. При сравнении же форм высказываний на двух языках - при условии предваряющего анализа выражения содержания высказывания в тексте изучаемого языка (подлинника) и возможности перевода раскрыть способы этого содержания в данном языке - одни и те же понятия семантики освещаются в точки зрения активной грамматики.

Чтобы глубже постичь особенности заимствованных слов, не имеющих расхождения в написании и в семан- 
тике, необходимо сравнивать их с узбекским языком не только на уровне языка, но и на уровне речи, не только в плане пассивной грамматики, то есть анализа текста, но и в плане активной грамматики, то есть анализа способов выражения данного оттенка значения; нужно прослеживать отношение средств выражения к описываемой ситуации с целью выявления тех аспектов, которые с наибольшей полнотой и последовательностью отражаются в узбекском языке. А поэтому необходимо учитывать все пласты лексики: и обиходно-разговорную лексику, и специальную, в том числе терминологию спортивной лексики.

Следует также иметь в виду, что «чтобы постичь закономерности употребления слов, нужно рассматривать их на фоне взаимодействия уровня мышления (план содержания) и уровня языковых форм (план выражения). В акте речи мы имеем дело не с отдельным словом, а с целым высказыванием (план выражения), которое описывает не отдельный предмет, а ситуацию, причем понятия, передаваемые словами и грамматическими формами, образуют план содержания» [9, с. 6263]. Сопоставление разносистемных языков помогает учесть не только действия грамматических законов заимствующего языка, проявляющихся как в сходстве, так и в различиях семантики, но и выработать у учащихся динамический стереотип, заключающийся в вычленении, например спортивных слов и выражений из потока речи и самостоятельном их использовании в соответствующих жизненных ситуациях.

Далее, говоря о действии грамматических законов заимствующего языка, необходимо учитывать изменение грамматических форм в определенной части заимствованных слов. Например, множественное число существительных, не подвергшихся в номинативной форме деформации (лагеръ, чемпион и др.), образуется 
в узбекском языке с помощью суффикса -лар: лагерлар, чемпионлар. Поэтому внешний облик склоняемого существительного в спортивной литературе на русском языке может быть непонятен учащимся-билингвам.

Изменение форм может также наблюдаться «при орфографической трансформации, узбекизированной грамматической форме, прибавлении узбекских аффиксов, добавлении вспомогательных слов и т. п.» [7, с. 93].

Это объясняется:

- различиями фонетической и грамматической систем русского и узбекского языков: менеджер - менекер, музыка - музика;

- употреблением заимствованных слов в узбекском языке без суффиксов (если слово в русском языке с нулевой флексией) или без суффиксов и окончаний: минута - минут, шахматы - шахмат, шашки шашка;

- добавлением узбекских аффиксов к заимствованным словам: интенсивность - интенсивлик, парашютист парашотист, парашютчи, секундометрист - секундометрист, секундомерчи, спортсмен - спортсмен, спортчи, тренерский-тренер, тренерлик, футболист - футболист, футболчи, хоккеист - хоккеист, хоккейчи;

- заимствованием из русского языка при участии вспомогательных узбекских слов килиш, бериш и др.: импровизачия - импровизачия килиш, инструктаж - инструкиия бериш, классификаиия-классификаиия килиш. Этот процесс сопровождается прибавлением узбекских аффиксов к заимствованным словам, а иногда и к узбекизированным грамматическим формам: гимнастика- гимнастикачи аёл.

Подобные слова спортивной терминологии, как уже указывалось выше, оттеснены нами ко второй группе частично различающейся лексике. В эту группу вошли также слова, подвергшиеся частичной деформации: 
культуризм - културизм, мат - мот, ферзъ - фарзин, шаш-

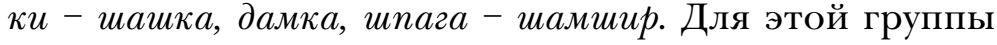
слов в отдельных случаях характерен синонимический ряд перевода на узбекский язык:

\begin{tabular}{|l|l|}
\hline В русском языке: & В узбекском языке: \\
\hline гимнастика & гимнастика, бадан тарбия \\
дистанция & дистанция, масофа, оралик \\
доска & доска, тахта, лавха, \\
мастер & мастер, уста, устоз, омилкор, мохир. \\
ритм & ритм, вазк, маком, оканг, биртекис. \\
\hline
\end{tabular}

Третью, наиболее многочисленную группу составляет спортивная лексика, являющаяся по звуковому облику и написанию совершенно разной в русском и узбекском языках:

\begin{tabular}{|l|l|}
\hline В русском языке: & В узбекском языке: \\
\hline бревно & ёгоч, хода, гўла \\
брус & тўсин, тўрт, ёгоч тўоин \\
вздох & нафас олиш \\
возраст & ёш, хамла, хамла килиш (киличвозлик спортида) \\
голова & бош, калла \\
движение & харакат, юриш, кимирлаш и др. \\
\hline
\end{tabular}

Изучение лексико-семантических групп спортивной тематики в русском и узбекском языках позволило глубже раскрыть семантику и функциональное своеобразие словарного состава каждого из сопоставляемых языков. Прежде всего нами отмечены случаи полного совпадения значений спортивных терминов: гимнаст, гиря, организм, ориентир, очко, палатка, парашют, пингпонг, позичия, старт, чемпионат и др.; частичного совпадения значений: сужение значений в узбекском языке команда совпадает в пяти значениях из шести, кроме (начальство) команда, командирлик, принять команду; про- 
грамма (совпадает одно значение из пяти: программа и устав партии - партия программа ва устави); чемпион (совпадает одно значение из двух, а именно: спортсмен или спортивный коллектив), победитель в соревнованиях по какому-нибудь виду спорта на первенство города, страны и т. д.); расширение значений в узбекском языке. Например:

\begin{tabular}{|l|l|}
\hline Награда (рус.) & Мукофат (узб) \\
1. Особая благодарность, почетный & 1. Награда, премия \\
знак, орден и т. п., которыми & 2. Редк. воздаяние. \\
отмечают чьи-нибудь заслуги. & \\
\hline Сетка (рус.) & Тур (узб.) \\
1. Небольшая сеть различного & 1. (еть, сетка \\
назначения (мяч в сетке) & 2. Кружева \\
2. Сумка для ношения продуктов, мелких & 3. Сетка, сетчатый узор на \\
вещей (разг.) & поверхности дыни \\
3. Расчерченная, обычно в клетку, & 4. Почетное место в комнате \\
поверхность. & 5. Сторона противоположная \\
4. Расписание, шкала (спец.) & входу \\
\hline удар (рус.) & Зарб, зарба (узб.) \\
1. Резкий, сильный толчок, & 1.Удар, сила. \\
прикосновение к чему-нибудь ссилой. & 2. (уст.) чеканка \\
2. Звук, от такого толчка, а также & 3. (уст. матем.) умножение \\
вообще отрывистый звук, стук. & 4.(уст. муз. лит.) ритм \\
3. (перен.) стремительное нападение, & 5. Отпор \\
атака. & б. (перен.) вред, ущерб \\
4. (перен.) тяжелая неприятность, & 7. Паралич \\
потрясение. & 8. Толчкообразное колебание \\
5. Кровоизлияние в мозг, паралич. & (сердца, пульса). \\
6. Толчкообразное колебание (сердиа, & \\
пульса). & \\
\hline упражнение (рус.) & Машк (узб.) \\
1. Упражнять & 1. Упражнение, тренировка \\
2. Задание, выполняемое тем, кто & 2. Муз. игра на музыкальном \\
упражняется в чем-нибудь & инструменте. \\
\hline
\end{tabular}

Как видно из приведенных примеров, расширение значений в узбекском языке осуществляется в основном 
за счет терминов, экзотизмов, устаревшей лексики и лексем, употребляемых в переносных значениях.

Кроме того, в спортивной лексике узбекского языка наблюдаются специфические некоторые семантические явления. К таким явлениям следует отнести прежде всего лексическое неразличение некоторых понятий. Так, в узбекском языке понятия «идти» и «ехать» выражаются словами бормок и юрмок, «стоять»и «лежать» (в значении «находиться») - турмок. Характерно, что носители узбекского языка, даже хорошо владеющие русским языком, в своей русской речи нередко вместо глагола «ехать» употребляют «идти», вместо глагола «лежать» - «стоять»и наоборот. В данном случае речь идет о недифференцированном обозначении этими словами различных понятий.

С точки зрения семантики, определенный интерес представляет структура некоторых слов, являющихся названиями частей тела. Например, выражение лицом к личу, с глазу на глаз, нос к носу в узбекском языке переводятся как юзма-юз, где юз - лицо. Это говорит о том, что при образовании понятия «лицо» глаза и нос взяты как основные признаки лица: встретиться нос к носу юзма-юз келиб колмок, личом к лищу - юзма-юз, с глазу на глаз - юзма юз.

Итак, анализ литературы по сопоставительной лексикологии применительно к спортивной лексике показал, что в узбекском языке имеется немало слова заимствованных из русского языка и через него узбекским языком, относящихся к спортивно-физкультурной терминологии (баскетбол, бокс, волейбол, гимнастика, дзюдо, регби, теннис, хоккей, футбол и т.д.). Сюда же относятся и слова, общие по значению в русском и узбекском язы-

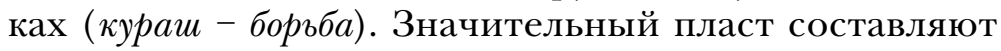
слова, относящейся к биологическому подстилю (глова, лицо, нога, рука, туловище и т. д.), а также общеупотреби- 
тельная лексика, являющаяся материалом для образования составных терминов: спортивная гимнастика, спортивный зал, соскок с вытянутыми вперед руками и т. д.

Проведенное сопоставительное изучение спортивной лексики выявило необходимость использования в обучении русскому языку конкретных межъязыковых сопоставлений, что может содействовать осознанному изучению русского языка учащимися-узбеками, пополнению лексического состава и развитию эффективной русской речи, а также раскрытию внутреннего богатства сопоставляемых языков, вооружению учителей ценным лингводидактическим материалом, который придаст и профессиональную уверенность в процессе обучения русскому языку учащихся-узбеков.

Вместе с тем выявление специфики спортивного пласта лексики позволяет прогнозировать качественное усвоение других лексико-семантических групп современного русского языка на основе разработанных эффективных систем упражнений с учетом сопоставительной характеристики соответствующих лексических единиц в русском и узбекском языках.

\section{Лumepamypa:}

1. Андриянова В.И. Актуальные вопросы обучения русской речи в узбекской школе // Русский язык в национальной школе. 1973. № 6. С. 30-36.

2. Бондаревская Е.В., Кульневич С.В. Педагогика: личность в гуманистических теориях и системах воспитания: учеб. пособие для студ. сред. и высш. пед. учеб. заведений, слушателей ИПК, учителей. М.; Ростов н/Д.: Учитель, 1999. 563 с.

3. Гак В.Г. Сопоставительная лексикология. М.: Междунар. отношения. 1977. 264 с.

4. Киссен И.А. Курс сопоставительной грамматики русского языка (Фонетика, морфология, синтаксис). Ташкент: Укитувчи, 1966. 35 с.

5. Поливанов Е.Д. Опыт частной методики преподавания русского языка. Изд. 3-е, доп. Ч. 1. Ташкент: Укитувчи, 1968. 128 с. 
6. Солнцева Л.И. Активизация русских лексических заимствований в узбекском языке на уроках русского языка в 4-м кл. узбекской школы. Автореф. дис. ... канд. пед. наук. Ташкент, 1981. 19 с.

7. Тохтаходжаева М.Х. Двуязычные учебные словари и принципы их сопоставления. Ташкент: Укитувчи, 1981. 182 с.

8. Ураева Э.У. Обогащение речи старших классов узбекской школы многозначной глагольной лексикой русского языка. Автореф. дис. ... канд. пед. наук. Ташкент, 1990. 19 с.

9. Успенский М.Б. Совершенствование методов и приемов обучения русскому языку в национальной школе. М.: Педагогика, 1979. 134 с.

10. Шанский Н.М. Русское языкознание и лингводидактика: сб. ст. М.: Русский язык, 1985. 239 c.

11. Щерба Л.В. Языковая система и речевая деятельность. Л.: Наука, 1974. 152 с.

\section{Marina Tsoy, \\ Lecturer, the Uzbek State University of World Languages (Tashkent), tsoymarisha@yandex.ru \\ Comparative characteristics of sports vocabulary in the Russian and Uzbek languages for lingual-didactical purposes}

The article discusses the classification and analysis of the differential and the common in sports vocabulary of the Russian and Uzbek languages. It is considered to be one of the most important conditions for the scientifically grounded development of a methodology for its assimilation by bilingual students, and of a system for the formation of both lexical and grammatical, and communicative skills. An attempt has been made to conditionally divide the sports vocabulary layer into three groups. The first group of words includes those that convey the designations of the same concepts in the Russian and Uzbek languages. The second group included vocabulary partially differing both graphically and in grammatical function. The third and most numerous group is sports vocabulary which is completely different in sound appearance and spelling in the Russian and Uzbek languages.

Keywords: bilingual students, the Uzbek language, multi-system languages, sports vocabulary, juxtaposition, translation, lexical meaning, borrowings, pivot words, scientific substyle. 